\title{
FLOOD HAZARD MAPPING AT LONG XUYEN QUADRANGLE IN 2015 USING GEOGRAPHIC INFORMATION AND REMOTE SENSING
}

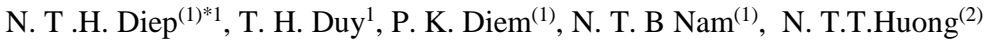 \\ (1) Land Resources Department, College of Environment and Natural Resources, Can Tho University \\ ${ }^{(2)}$ Forest Ecology and Environment Department, Faculty of Agriculture and Forestry, Tay Nguyen University
}

KEY WORDS: MNDWI, flood distribution, Long Xuyen quadrangle, correlation coefficient

\begin{abstract}
In recent year, the flooding has been occurred with higher frequency at Long Xuyen Quadrangle areas of Mekong Delta, Vietnam. It was considered as a major natural disaster which effects on the physical and spiritual in people's life in this area. This research aims to generate a flood hazard map and assess the flood situation at Long Xuyen quadrangle in 2015. The MNDWI (Modification of Normalized Difference Water Index) extracting from Sentinel 2 image was used to map the flood extent at Long Xuyen quadrangle during rainy season in 2015. The statistics method was estimated correlation coefficient between flooding spatial distribution and hydrological stations on SPSS software. The results showed that the severe flood occurred from August to December in 2015. There were about 47.6\% and $28.2 \%$ of the total area were inundated in October and August, respectively. The correlation between inundated areas and water level at Ha Tien and Chau Doc hydrological stations was 0.73 and 0.65 (p $<0.01$ ), respectively. The derived information was very essential and valuable for local managers in making decision on responding and mitigating to the flood disaster.
\end{abstract}

\section{INTRODUCTION}

Long Xuyen Quadrangle (LXQ) is the largest rice-producing region in Mekong River Delta (MRD). Above all, rice production in the Mekong Delta have particularly important role in ensuring national food security and contributing positively in exports. However, the face of climate change makes flood in Mekong Delta region in general and in LXQ in particular that has a large variation between in the year of the large flood and the small flood. Water level rise in river caused on widespread flooding making serious damage to manufacturing, property and human life in the years of largescale flooding. Damage also brings a significant in the years of the small-scale flooding, because water level in the upstream reducing the amount of water stored in the basin causing of increased salinity intrusion in the dry season affecting agricultural production (L.V. Thuan., 2009).

Nowadays, remote sensing technology is a powerful tool in manage of natural resources to

\footnotetext{
${ }^{*}$ Corresponding author
} 
monitor natural phenomenon with the ability to provide data on the vast space, repeated cycle, remote sensing data becomes the useful for researchers, manage the implementation of its projects in particular for monitoring of flooding situation (Sakamoto, t. et. al., 2007). Therefore, the use of remote sensing technology to become more superior with Sentinel-2 data had provided multi-temporal image, covering a large space, saving time and costs for the reserach in flood that will be more effective and innovative applications.

For all above reasons, the research of "Flood hazard mapping at Long Xuyen Quadrangle in 2015 using Geographic Information System and Remote Sensing" to assess current flood map in Long Xuyen Quadrangle in 2015, thereby giving timely solutions to limit the damage caused by floods that are a basis for management, flood forecasting to support the managers having an overview and providing timely solutions limited damage caused by flood.

\section{STUDY AREA}

According to Le Sam (1996), Long Xuyen Quadrangle (LXQ) is a region belong to the Mekong Delta including three province of Kien Giang, An Giang and Can Tho city, in which about $52 \%$ of the area in An Giang Province, about $46 \%$ in Kien Giang Province and the rest in the North Cai San of Vinh Thanh district, Can Tho city (2\%). The four edges of LX quadrangle include the Vietnam - Cambodia border, Kien Giang's Gulf, Cai San canal and Hau River. The area of LXQ region is about 489,000 hectares. The terrain is relatively flat with absolute height from 0.4 to 2 meters (Figure 1).

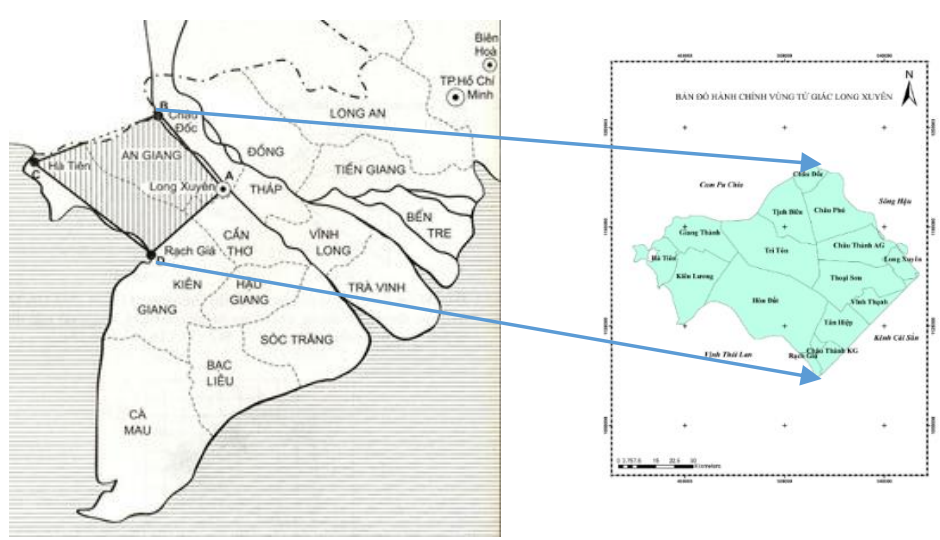

Figure 1: Long Xuyen Quadrangle's administrative map

\section{METHODOLOGY}

\subsection{Data collection}

Remote sensing image: Sentinel-2 images were collected from August to December in 2015 by the European Space Agency (ESA) with the characteristics are described in Table 1. The temporal resolution is 12 days and spacial resolution are 10 meters and 20 meters. The total scene of Sentinel-2 images were collected by 12 scenes to cover whole study area.

Field data collection: water levels data collected in each month from August to December, 2015 in two hydrology stations of Ha Tien and Chau Doc.

\subsection{Satellite image processing}

Sentinel images to integrate between high resolution images $(10 \mathrm{~m})$ and low resolution images $(20 \mathrm{~m})$ to create the imagery with high resolution (10 meters $)$ and multi-spectral imaging. 
The Modified Normalized Difference Water Index (MNDWI) to determine the water index images as follow the formula $(\mathrm{Xu}, 2006)$ :

MNDWI $=\frac{(\text { Green }-M I R)}{(\text { Green }+M I R)}$

in which green is green band (channel 3 of the Sentinel-2); MIR is a middle infrared band (channel $8 \mathrm{~A}$ of the Sentinel-2). And image classification using ISODATA method of unsupervised classification.

\subsection{Comparions of flood and field data}

Data collection in $\mathrm{Ha}$ Tien and Chau Doc stations from August to December, 2015. Applying linear regression to assess correlation coefficients $\left(\mathrm{R}^{2}\right)$ to demonstrate the relationship between image classification and data collection in hydrologie stations.

\section{RESULTS AND DISCUSSION}

\subsection{Flood distribution in LXQ}

From the results of flood in each month from August to December in 2015 in are shown in Figure 2. December 2015. The flooded area in August was 137,682.64 hectares, accounting for $28.2 \%$ of total LXQ area; in September flooded area was increased to $191,920.05$ hectares, accounting for $39.2 \%$ of total LXQ area comparing to in August to increase 54,237.41 hectares. In October, maximum flooded area reached 232,734.92 hectares, accounting for $47.6 \%$ of total LXQ area increasing compared to in September of $40,814.87$ ha. In November, flood area of 187,682.64 hectares, accounting for $38.4 \%$ of total LXQ area, the flooded area was decrease compared to October of 45,052.28 hectares. The last month of December, flood area receded considerably with 145,776.84 hectares, accounted for $29.8 \%$ of total LXQ area that is lower than in November of $41,905.8$ hectares. The flooded area variation between the highest flood area in October and the lowest flood area in August about 95,052.28 ha.

Figure 2 shows the distribution of flood changes in each month including (August, September, October, November and December. In LXQ region, the level of flooding submerged reaching a peak in October and minimum flooded area is August. The reason is that LXQ is a particular area of flood due to Mekong River to start of flood in August and when the southwest monsoon starts blowing, the rainy season begins in the basin that is the time of the upper and middle of Mekong River also began rising.

Flood season usually extends from at the beginning of August to the end of December and is divided into three phases. When the water level on the main river rising into a certain level to be overflown flowing to branch river, canal to flow into the field as flooded area also increase. For LXQ, flooding is usually extended from at the beginning of August to the end of December every year and is divided into 3 phases, the first phase from the beginning of water level in the main river increase and flowing from canals into the field between at the beginning of August to the end of September. And then the peak flood period, depending on flood flowing sooner or later in years, flood peak also appeared with the corresponding period in October in years. The final stage is the time when the flood waters receded and usually start at the beginning of November to the end of December, the lower the water level gradually (Figure 2). 


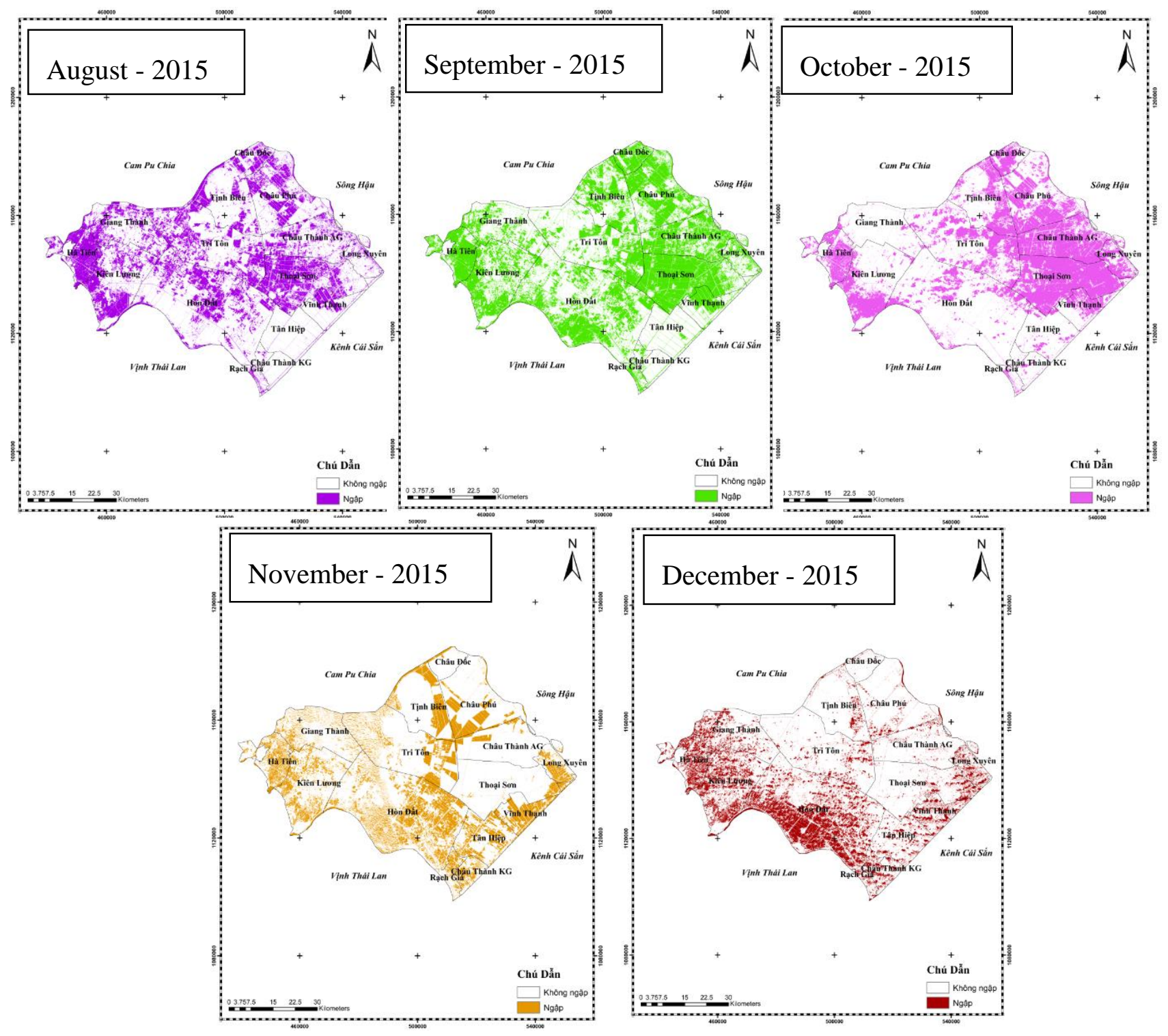

Figure 2: Flood maps distribution from August to December, 2015 in LXQ

\subsection{Flooded changes areas in Long Xuyen Quadrangle}

The flood area and non-flood area were determined on image classification. The process changes of flood area movement in LXQ in 2015. In August, flood area began inundation around 137,682.64 hectares, accounting for $28.2 \%$ of the LXQ area, the lowest flooded area happening in this month. In September, flooded area increased gradually and reached to
191,920.05 hectares wit 39.2\% of the LXQ area. Peak flood began in October with an area going up to $232,734.92$ hectares, occupy $47.6 \%$ of the LXQ area. From November to December, flood significantly reduced compared with the flood peak period with flooded area is turn into of $187,682.64$ ha $(38.4 \%)$ and $145,776.84$ ha (29.8\%). Flooded progress in LXQ coincides with the rainy season and floods in the study site to appear in certain periods and less changes (Figure 3). 


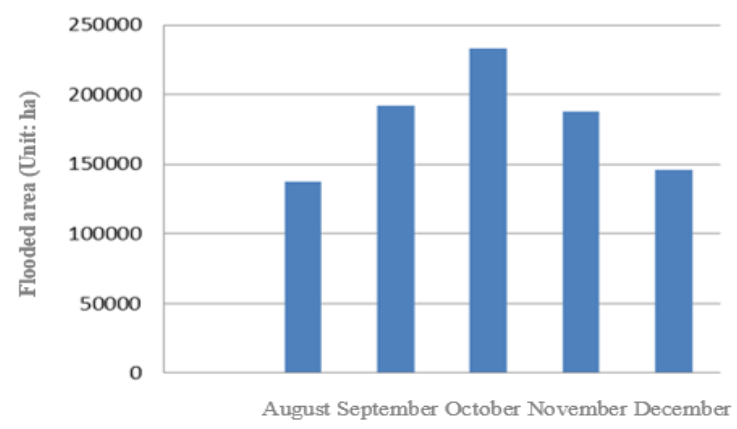

Figure 3: Flooding area in the LXQ region in five months from August to December

Figure 3 shows the flood of LXQ began appearing in August, flood peaking in October and flood ending in December in 2015. Figure 3 shows that five months of research in the upstream district began current flood area, then extending to the neighboring districts. The flooded area started in August and increasing in September approximately corresponds to the beginning of the flood season in LXQ. Flood peak in October and decreasing in two months of the end in year of November and December. Figure 2 provides an overview of water area changes in different times and that is a basis to determine flood movements as well as water level in 2015.

Also, Figure 3 shows surfacce water area in three provinces in LXQ different due to each in the study site. However, fluctuations of flood is a general rule, the area of the water began to rise in August, September and peaked at a certain time in October then decrease in the last 2 months.

\subsection{Long-period fluctuations in moonsoon floods in the Long Xuyen Quadrangle}

Figure 4 shows the flooding in An Giang province with the most flooded areas to distribute in the LXQ. Flood was appearing in
August and September and peaked in October and the flood waters receded gradually in November, then fell sharply in December. The causes of flooding were occurred to appear in the upstream area thus the most districts in An Giang province are affected first, then moving to any direction and expanded corridor surrounding districts due to low terrain area.

Besides, Figure 4 also shows the flood peaks in Kien Giang province in August, falling in September continuing to increase in October and then decreasing gradually in November and keeping to extend in December. The cause is that flood occurs in the upstream and expanding in the low terrain. Kien Giang is the border of the West Sea leading to flood drainage capacity having some difficulties because of the sluice gates along coastal area.

In Can Tho city, Vinh Thanh district, flood affected almost primarily in November. The reason of Vinh Thanh is the last district of LXQ, thus flood begins later than and the flood flow also decline in this region (Figure 4).

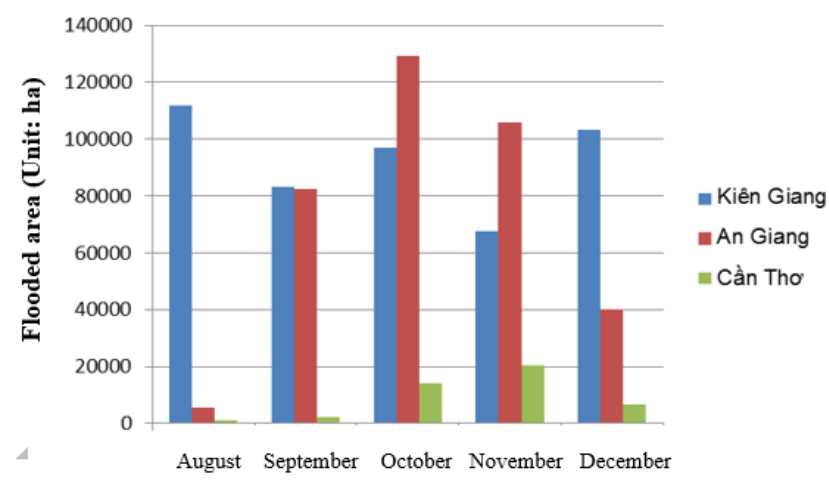

Figure 4: The fluctuation of flooded area in three provinces belong to LXQ

\subsection{Comparing flood situation and filed data}

In the rainy season, water level in the river rises exceeding a terrain leading to overflowing from rivers or canals into the field. The flooded are is 
increasing with the overflow from the river, the water level will be higher and higher on the field. The study conducted the correlation between the flood area in Kien Giang and An Giang provinces to classify from images Sentinel-2 and water level data recording from hydrological stations of Ha Tien and Chau Doc. Monitoring data was collected to a period of flood season at the beginning of August in 2015 to the end of December, 2015. The correlation between the flooded area in Kien Giang and An Giang provinces with water levels of hydrological data are shown specifically on Figure 5.
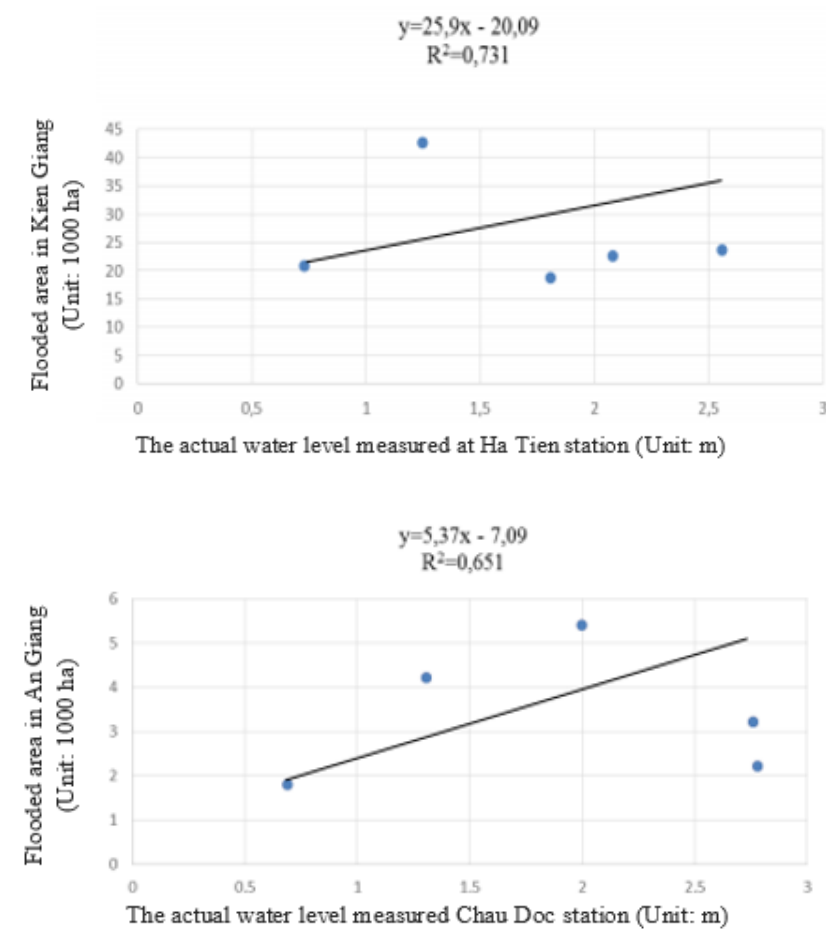

Figure 5: Correlation coefficients between the flooded area and hydrological stations.

The results show the positive correlation between flooded areas and monitoring data at two stations of Ha Tien and Chau Doc with high correlation coefficients at 0.731 and 0.651, respectively. The result has provided a better overview of the current river flood in LXQ in spatial and temporal variability of flood seasonality in 2015. From the comparable results, flood monitoring in LXQ in the year of 2015 using satellite imagery Sentinel - 2 has a significant statistics.

\section{CONCLUSION}

This research was created spatial and temporal distribution of flood using Sentinel-2 image data for an overview of the current flooded distribution in LXQ in 2015. The spatial progress of flooded during five months from August to December 2015 shows the flood peak discharge in October and ending in December in LXQ region and the current flood maps in each month has been established using Sentinel-2. Flood affected in three provinces of An Giang, Kien Giang, Can Tho in which the districts in upstream including Chau Phu and Tinh Bien (An Giang province); Ha Tien and Hon Dat (Kien Giang province) covering an affected area by the floods at most compared to the remaining districts in the region. The result of flooded area precision have high correlation based on a comparison between the flooded area and water levels at hydrological stations Ha Tien and Chau Doc with $\mathrm{R}^{2}$ equal 0.731 and 0.651 , respectively.

\section{REFERENCES}

Doan Thanh Chung, Tran Thi Luan and Tran Van Binh, 2010. Documentation planning flood prevention and storm the provincial, district Regional provinces and the Mekong Delta. Administration dikes and flood prevention. Hanoi.

ESA Sentinel - 2 Team, 2007. GMES Sentinel 2 Mission Requirements Document.

ESA, 2015. Sentinel-2 User Handbook. 
GAO, BC., 1996. NDWI - a normalized difference water intex for remote sensing of vegetation liquid water from space. Remote Sensing of Environment, 58, pp. 257 - 266.

General Department of Water Resources Bureau flood dikes and flood prevention, the 2010 Guide to plan prevention and control of floods and storms provincial and district area Mekong Delta. Ha Noi Agricultural Publishing House.

Irrigation Planning Institute of Southern, 2009. Assessing the impact of flood control and irrigation works infield to environmental flows and economic development in floodprone areas Mekong Delta. [Access Date 02.01.2016]. Address counter:.

L. V. Thuan, 2009. Evaluation of the Impact of Flood Control and Country Hydraulic Project to Environmental Flow and Economic Development in Flood area of Mekon Delta. Irrigation Planning Institute. Journal of Science and Technology of Irrigation Planning, Viet Nam
Lillesand, T.M., Kiefer, R.W., 1979. Remote Sensing and Image Interpretation, John Wiley and Sons, New York.

Nguyen Hieu Trung and Nguyen Dinh Giang Nam, 2010. Management and flood mitigation. Environment and Natural Resources College, Can Tho University.

Sakamoto, T., Nguyen, N. V., Kotera, A., Ohno, H., Ishitsuka, N., and Yokozawa, M. 2007. Detecting temporal changes in the extent of annual flooding within the Cambodia and the Vietnamese Mekong Delta from MODIS time-series imagery, Remote Sensing of Environment, 109(3), 295-313.

Thomas M.Lillesand \& Ralph W.Kiefer, 1996. Remote sensing and image interpretation, University of Wisconsin, Madison, USA.

Tran Tien Khanh, 2001. Try to find out the causes massive flooding in the Mekong Delta. Access Date 22.08.2015 